\title{
CVD and obesity in transitional Syria: a perspective from the Middle East
}

\author{
This article was published in the following Dove Press journal: \\ Vascular Health and Risk Management \\ 5 March 2012 \\ Number of times this article has been viewed
}

\author{
Hani Barakat ${ }^{\prime}$ \\ Hanniya Barakat' \\ Mohamad K Baaj ${ }^{2}$ \\ 'Kalamoon Private University Medical \\ School, Deir Attieh, Syria; ${ }^{2}$ Aleppo \\ University Medical School, Aleppo, \\ Syria
}

Purpose: Syria is caught in the middle of a disruptive nutritional transition. Its healthcare system is distracted by challenges and successes in other areas while neglecting to address the onslaught of Syria's cardiovascular disease (CVD) epidemic. Despite the official viewpoint touting improvement in health indicators, current trends jeopardize population health, and several surveys in the Syrian population signal the epidemic spreading far and wide. The goal is to counteract the indifference towards obesity as a threat to Syrian's health, as the country is slowly becoming a leader in CVD mortality globally.

Methods: PubMed, World Health Organization, and official government websites were searched for primary surveys in Syria related to CVD morbidity, mortality, and risk factors. Inclusion criteria ensured that results maximized relevance while producing comparable studies. Statistical analysis was applied to detect the most common risk factor and significant differences in risk factor prevalence and CVD rates.

Results: Obesity remained the prevailing CVD risk factor except in older Syrian men, where smoking and hypertension were more common. CVD mortality was more common in males due to coronary disease, while stroke dominated female mortality. The young workforce is especially impacted, with $50 \%$ of CVD mortality occurring before age 65 years and an $81 \%$ prevalence of obesity in women over 45 years.

Conclusion: Syria can overcome its slow response to the CVD epidemic and curb further deterioration by reducing obesity and, thus, inheritance and clustering of risk factors. This can be achieved via multilayered awareness and intensive parental and familial involvement. Extinguishing the CVD epidemic is readily achievable as demonstrated in other countries.

Keywords: Syria, CVD, obesity, risk factors

\section{Introduction}

The cardiovascular disease (CVD) pandemic worldwide presents a true challenge today with a high health burden that is only expected to rise. Most of the deaths in the world are due to noncommunicable diseases and more than half of these are due to CVD. Although initially endemic to industrialized countries, CVD today is well advanced in even the poorest of developing countries according to World Health Report 2003. ${ }^{1}$ Yet the global health agenda prioritizes communicable diseases before CVD. In reality, developing countries are facing a "double burden" of noncommunicable diseases on top of the communicable diseases exacerbated by the human immunodeficiency virus. Twice as many deaths from CVD occur in developing countries compared to developed countries; additionally, the early age of CVD death in developing countries compared to developed countries is of particular cause for concern. ${ }^{1}$
Correspondence: Hani Barakat 2510 S Wilmington St, Raleigh,

NC 27603, USA

Tel + I 9197804264

Email abunedol@hotmail.com 
Risk factor (eg, smoking, hypertension, obesity) clustering accelerates CVD exponentially rather than synergistically, especially in Pacific and Middle Eastern countries such as Syria. ${ }^{2}$ Furthermore, the economic burden of CVD is expected to rise with countries spending at least $40 \%$ of their healthcare budgets on CVD complications. ${ }^{3}$ Given the high health and economic cost in the Middle East, CVD prevention is of prime importance.

International involvement in the Middle East rarely occurs with the help of local expertise or experienced local researchers that are able to draw from international experience while capitalizing on local strengths. ${ }^{4}$ Also, little public involvement in the decision-making process is an impediment. The brain drain is an additional challenge in cultivating scientific leadership and disease activism in transitional Syria, which calls for the encouragement and sponsorship of more researchers and expanded funding for research while involving the public. Success in Syria against infectious disease and malnutrition increased life expectancy and decreased child mortality and childbirth-associated mortality. Many of the previous successes in Syria were not based on epidemiological data or methodical population research, which has left the health system accustomed to recycling outside knowledge and applying it in Syria regardless of applicability.

The Health Sector Modernization Program (HSMP) in 2007-2009 exemplifies international involvement by the European Union and cooperation with national authorities in the Ministry of Health despite mixed success (http:// hsmp.moh.gov.sy). Over the years, the healthcare system in Syria suffered embargoes, an influx of refugees, and overcrowding due to a population boom. HSMP responds to strain on the healthcare system by focusing on expanding capacity and quality assurance, implementing modern management, and establishing the Center of Strategic Health Studies (http://cshs.moh.gov.sy). Despite encouraging outcomes in the healthcare infrastructure, HSMP falls short in the improvement of record keeping and surveillance of disease. Such trends and apathy to population research is the reason CVD in Syria is often left out of discussion and planning. Although Syria is at the forefront of Middle Eastern countries in establishing a population research center and private medical education, CVD research continually lags.

The rationale behind this study is to assess CVD risk factor determinants in Syria and evaluate policy approaches in face of the epidemic CVD transition in Syria. This is the first systematic review of obesity or CVD in Syria and recommendations are offered to curb further deterioration towards obesity and CVD in future generations of Syrians and to sidestep this important impediment to productivity and development in Syria. This review approaches obesity, the major contributor to CVD in Syria, as a vertically transmitted disease requiring multilayered awareness and intervention in society and intensive parental and familial involvement.

\section{Methods}

PubMed, World Health Organization, and official government websites were searched for primary surveys in Syria related to CVD morbidity, mortality, and risk factors using keywords within the string: ("prevalence Syria" and ["CVD" or "obesity" or "body mass index [BMI]" or "smoking" or "hypertension" or "stroke" or "heart disease" or "hypercholesterolemia"]). Results were filtered based on inclusion and exclusion criteria, which maximized relevance while producing comparable studies. No studies that included less than 200 subjects or strictly nonSyrian nationalities were accessed. Statistical analysis was applied to detect the most common risk factor and significant differences in risk factor prevalence and CVD rates among subgroups.

\section{Results \\ Studies of relevance and populations surveyed}

Exclusion criteria and low relevance precluded 69 references, resulting in the inclusion of only six references. All the results reviewed here pertain to the Burden of Disease $(\mathrm{BoD})$, Stepwise, Aleppo Household Survey (AHS), and Adolescent Obesity (AOS) surveys, in respective order of decreasing size and geographic national representation. BoD and Stepwise, sponsored jointly by the Syrian Ministry of Health and World Health Organization, were the sole surveys spanning all Syrian provinces; AOS and AHS were limited to the capital, Damascus, and Aleppo City, respectively. Overall these surveys are of good quality with controls on confounding variables including age, race, and socioeconomic status. ${ }^{5}$

\section{Summary of available CVD and risk factor data}

BoD provided aggregate CVD mortality from death certificates collected by the Central Bureau of Statistics during 2002 and again in 2005. ${ }^{6,7}$ Another separate estimate of 5-year CVD mortality was provided by AHS based on verbal autopsy from 1021 Aleppo residents during 2004, 
representing the second major metropolitan center in Syria (population $\sim 2.5$ million).

In addition to CVD mortality, AHS also provided risk factor measures in Aleppo. Separate risk factor measures (without CVD mortality) were also available from 9152 subjects throughout Syria under Stepwise. Finally, obesity prevalence was measured in the schools of Damascus for 778 adolescents by AOS. All the papers employed a uniform definition for obesity as adopted by World Health Organization.

\section{Main CVD mortality findings}

Presenting the main findings of surveys highlights Syria's overwhelming epidemic. Overall CVD mortality in Syria, according to $\mathrm{BoD}$ in 2005 , was high at $49 \%$ with a $10 \%$ increase from the preceding 3 years. AHS estimates found CVD mortality at $45 \%$ with no difference from Stepwise $(P<0.05) .{ }^{8}$ These are very high mortality rates compared to the average in developing nations $(23 \%)$ and even to surrounding countries. ${ }^{7}$ CVD mortality in neighboring Jordan registered $35 \%$ of all deaths for example. The uncontrolled rate of annual increase in CVD mortality at 3.3\% is particularly concerning. No comparable country in the Middle East supersedes Syrian CVD mortality. According to AHS, about half of CVD mortality occurs before the age of 65 years compared to only one-fifth occurring before the age 70 years in developed countries. ${ }^{9}$ CVD affected males predominately, due to coronary disease. Females suffered less total CVD mortality, mainly due to stroke.

\section{Obesity as the most common risk factor}

With the rising CVD health burden in Syria, risk factors were investigated for the population. According to Stepwise and AHS, obesity and overweight status were the most common risk factor in Syria overall, followed by hypertension. With regards to obesity, older females were the hardest hit subgroup, whereas with regards to risk factor clustering, undereducated older males were the most affected. CVD mortality invariably favored males. This paper focuses on obesity as the major CVD risk factor deserving of preventative measures given its clearly high prevalence as a precursor to clustering of other risk factors (hypertension, hypercholesterolemia) in Syrians. Obesity has an exceedingly important role in the pathogenesis and clustering of other risk factors despite the lack of awareness about its impact and little concern for it as a public health crisis.

According to Stepwise, overall obesity prevalence was $21.6 \%$ for those over 15 years compared to AHS registering $38.2 \%$ prevalence in those over 20 years. AHS found obesity especially rampant among Syrian women reaching 46.4\% prevalence, despite lower female obesity prevalence at $27.7 \%$ according to Stepwise. Only $41.2 \%$ of women enjoyed healthy BMI values in Stepwise. ${ }^{10}$ Syria's older female obesity prevalence at $46.6 \%$ soars compared to other Mediterranean countries that share similar nutritional patterns: Spain (15.2\%), Greece (15\%), and Turkey $(29.4 \%){ }^{11-13}$

Even more disconcerting is the fact that Syrian women in the AHS 45-65 years age group had very high obesity prevalence at $81 \%$. By all standards, there is a pressing need to slow the progress of the obesity epidemic in Syria. To put such an epidemic in perspective, it is suffice to say that Syria is a close second regionally behind Kuwait, which maintained the eighth position globally on overweight and obesity charts with $47 \%$ obesity prevalence. ${ }^{14,15}$ As obesity may have already peaked or stabilized in Kuwait, it is possible to see Syria overtaking all other regional countries on the BMI charts.

The second most common risk factor is hypertension with $20.1 \%$ overall prevalence, followed by hyperglycemia at $19.8 \%$, and hypercholesterolemia at $12.7 \%$. Needless to say, obesity is the major contributor to CVD in Syria and a corresponding spike in CVD mortality is observed. In fact, childhood obesity at $18.9 \%$ is an important factor igniting the CVD epidemic side-by-side with adult obesity, and such a role cannot be neglected as explained in the discussion below.

\section{Discussion}

Current or future Syrian CVD mortality may rise to among the highest in the world, with unreliable current projections at $85.3 \%$. No data exists to strengthen or deny that projection in the past 6 years, but the real figure may meet or exceed Bulgaria's world record for CVD mortality at around 67.5\%, especially given the fact that there are absolutely no initiatives aimed to combat CVD in Syria. ${ }^{16}$ The annual rate of CVD mortality increase at $3.3 \%$ depends also on the corresponding obesity spike, for which no current projections exist despite Syria's advanced rank on BMI charts.

Overall, most of the risk factors concentrate in the older population except for male obesity. Epidemiologically, a statistical problem presents itself in Syria and the Middle East. Since the age distribution vastly favors younger ages in the Middle East, surveys leaving younger ages unsampled miss much of the actual population. Stepwise, for example, reports risk factor prevalence for ages over 15 years while 
AHS includes ages over 20 years. This results in widely varying risk factor prevalence measures with AHS sometimes providing double the estimates in Stepwise. Stepwise is more nationally representative and thus estimates should be based on 15 years as the lower age limit. Ideally, all surveys in the Middle East should set 15 years as the lower age limit for sampling when not specifically targeting the pediatric population.

Analysis of obesity reveals obesity crossover from younger males to older females. AOS found male adolescent obesity 2.3 times that of female adolescents. Interestingly, the ratio is turned upside down in adulthood with female obesity increasing with parity. ${ }^{17}$ A likely confounding factor for decreased obesity in older males is the compulsory military draft.

Hypertension and smoking prevalence each surpass that of obesity in older men, thereby compounding exponentially their risk as obese children and overweight, hypertensive smokers. Childhood obesity is a stronger CVD predictor than adult obesity, with double the chance of early death for obese pediatrics. ${ }^{18,19}$ The average drop in life expectancy is 8 years for the young obese, even starting at 3 years old. ${ }^{19}$ Syrian men tend to suffer from childhood obesity, adult overweight status, hypertension, and smoking risk factor. Hypertension likely precipitates from childhood obesity while smoking spikes importantly from $12.1 \%$ in male teenagers to $47.7 \%$ in their twenties.

Adult female obesity is mostly an isolated contributor to CVD risk, hence greater CVD mortality in males. However, obesity still has a powerful role in pathogenesis, amplification, and clustering of CVD risk factors in both sexes. Hypercholesterolemia, refractory hypertension, and arthritis secondary to obesity compound CVD risk exponentially. Strong BMI effects on increased blood pressure remain linear while secondary hyperinsulinism causes upregulation of 3-hydroxy3-methylglutaryl-coenzyme A reductase, the same enzyme inhibited by statins. ${ }^{20,21}$

Mainly blaming high obesity prevalence in Syrian society, especially among Syrian women, on sedentary behavior does not properly address the problem source. Sedentary behavior by itself does not cause obesity and is not a risk factor for CVD. For example, sedentary behavior associated with playing videogames or during computer use does not increase obesity. ${ }^{22}$ Yet, watching television correlates strongly with obesity, which is likely due to a combination of food advertising bombardment, unoccupied hands (versus video gaming for example), and food readily in reach. The domestic roles of Syrian mothers and Middle Eastern females overall are not to blame for female obesity in Syria. Instead, enduring proximity to television stimuli and indoor food stimuli increases obesity, which is the more direct cause of increased clustering of CVD risk factors. ${ }^{22}$ Likewise, child obesity and CVD risk can be mitigated by distancing adolescents from obesogenic indoor activities regardless of the amount of exercise. Decreasing sedentary behavior may or may not decrease CVD risk. However, decreasing obesity ensures lower risk factor clustering, morbidity, and mortality.

Interestingly, inheritance of obesity as a hyperinflammatory state directly and indirectly from parents to offspring is demonstrated via epigenic inheritance, even in the absence of familial genetic obesity. A high-calorie diet affects metabolism, and the body adapts by epigenically regulating metabogenic and inflammatory genes such as those for insulin, leptin, and neutrophils, and adipocyte differentiation. The main response resembles epigenic changes such as methylation or demethylation in somatic and even germ-line cells. Atherogenic processes accelerate based on methylation patterns. ${ }^{23}$ Particularly worrying is the fact that germ cell changes seem to occur faster than somatic changes, and children born in these germ-lines possibly suffer a lifelong risk of CVD. Rat models confirm vascular dysfunction and atherogenesis in offspring to overnourished parents. ${ }^{24}$ Also, offspring to obese mothers gain $60 \%$ more weight on obesogenic diets compared to normal controls, while a similar epigenic effect is observed in male rats. ${ }^{25,26}$ Although weight loss in males is already achievable, female weight loss is a much more pressing issue as a precursor to child CVD and obesity.

Given the possible difficulty of introducing outdoor activities to women, household chores that involve standing or walking and little food preparation for the family aid in female weight loss and adolescent weight loss. ${ }^{27}$ Equally important, female awareness and empowerment via computer literacy, online home education, work-at-home initiatives, Islamic microfinancing, and even home exercise videos and fitness videogames facilitate weight loss and productivity indoors. Despite notions of suppression and helplessness, Middle Eastern females from all walks of life often have the main role in health advocacy and reform in the region. ${ }^{4}$

According to Stepwise, almost $99.1 \%$ of Syrians prepared and consumed food at home, where food preparation traditionally is a female responsibility. Yet, the adoption of 
Middle Eastern and Mediterranean diets in this Mediterranean country in the Middle East is frustratingly low even when the cuisine is among the best in the world for CVD prevention. ${ }^{28}$ Instead, emergence of high-calorie drinks and a westernized diet in the past decade is notable on top of urbanization causing a change in traditional food acquisition patterns. All Syrians are equal victims of this transition, with obesity spreading across all ethnic and socioeconomic lines. Only the educated are spared with less obesity and risk factor clustering (but more common overweight status).

A study of 3507 secondary school students during 2001 showed that more than $50 \%$ of students in Damascus and surrounding areas denied consumption of green vegetables over a whole week. ${ }^{29}$ Additionally, 35\% said they consumed cheese and milk at least once a day while only $11.8 \%$ consumed fruit three times or more per day. Stepwise found that only $4.2 \%$ satisfied the World Health Organization's minimum daily requirements for fruit consumption. Healthy food availability is not the problem, but diet and globalization are.

A preventative approach must aim towards repairing Syrians' diet to reduce access to high-calorie unhealthy foods and readopt more widely the original Mediterranean and Middle Eastern diets. A low-glycemic index diet is also the fastest and easiest approach to reduce CVD risk. ${ }^{30,31}$ Syrians must be cautioned against the extreme consumption of high-glycemic index foods such as white bread, white rice, and refined sugar, which are famously consumed in excess in Syria. In fact, outdated government policy mobilized against malnutrition subsidizes these unhealthy products, which heavily cost Syrians twice in subsidies and in health.

Government policy would be more profitable through taxation on obesogenic high-glycemic index products and smoking, in addition to subsidies for produce farmers instead of unhealthy food support. Many recommendations can be allied together in order to slow the epidemic via two arms: awareness and research. Awareness focuses on education to spread the message about protecting children's rights from prematurely falling victim to parental negligence and malnutrition along with expanded health education in curricula. Given the female obesity relationship to parity, breastfeeding is a big advantage in reducing both maternal and child obesity. ${ }^{32}$ Antichild obesity and antismoking campaigns and legislations should also exploit television media, internet, and online social utilities to reach males at an early age. The low-glycemic index diet is also by far the best starting point for the entire Syrian population. As for the second arm, greater funding is needed for research and surveillance data to monitor the response of the epidemic to interventions in population subgroups in cooperation with international organizations. Investment in research and prevention shortcuts much of the wasted resources and lost productivity. Also, medical education and training must foster more translational research instead of simply using didactic methods. Cooperation agreements with countries facing the same issues, or those that have found success in treating the epidemic, should be encouraged. ${ }^{33}$

Healthcare reform must continue to improve quality assurance where an improved nursing sector deserves the greatest attention through the provision of better working conditions and specialized nursing. Additionally, primary care must be strengthened as the first line of defense against chronic diseases. Also, greater involvement of the public using the latest public policy methods is of utmost importance based on approaches elsewhere. ${ }^{4} \mathrm{CVD}$ is usually quite responsive to prevention, and the future growth and development of Syria is unthinkable without overcoming a destabilizing impediment of such proportions. Syria easily has a chance to turn around the CVD epidemic and join other success stories in the world. ${ }^{1}$ The health effect is rapid, as seen in Mauritius where the government encouraged the consumption of healthy oils. Also, in Finland, subsidies to reduce dairy farming and increase berry production decreased CVD. In Poland as well, government policy to increase fruit consumption produced a sharp decrease in CVD. A similar effect is sought in Syria, but with an appropriate intervention for the Mediterranean and Middle Eastern environment.

Study limitations due to data shortage did not allow the comparison of urban to rural healthcare needs or drinkable caloric intake from beverages.

\section{Acknowledgments}

The authors thank Dr Ross Simpson for his encouragement and advice.

\section{Disclosure}

The authors report no conflicts of interest in this work.

\section{References}

1. World Health Organization. The World Health Report 2003. Geneva: World Health Organization; 2003.

2. Quinn ND, Grant PJ. Insulin resistance, thrombosis and vascular risk in type 2 diabetes mellitus. Pract Diabetes Int. 1999;16(Suppl 1): S255-S258. 
3. International Diabetes Federation. Metabolic Syndrome - Driving the CVD Epidemic. Brussels: International Diabetes Federation; 2004.

4. Gibson JM. A burden of disease approach to prioritizing environmental policy decisions: a case study in the Middle East. $N C$ Med J. 2011;72(2):136-140.

5. Hulley SB, Cummings SR, Browner WS, Grady DG, Newman TB. Designing Clinical Research. 3rd ed. Philadelphia, PA: Lippincot Williams and Wilkins; 2006.

6. Ministry of Health (Syria). Health Sector Modernization Program: burden of disease. 2007. Available from: http://hsmp.moh.gov.sy/ Default.aspx?tabid=70\&language=en-US. Accessed July 31, 2011.

7. World Health Organization. Chronic disease and health promotion. 2002. Available from: http://www.who.int/chp/chronic_disease_report/ syria.pdf. Accessed July 31, 2011.

8. Maziak W, Rastam S, Mzayek F, Ward KD, Eissenberg T, Keil AU. Cardiovascular health among adults in Syria: a model from developing countries. Ann Epidemiol. 2007;17(9):713-720.

9. Reddy KS. Cardiovascular diseases in the developing countries: dimensions, determinants, dynamics and directions for public health action. Public Health Nutr. 2002;5(1A):231-237.

10. World Health Organization. STEPwise approach to chronic disease risk factor surveillance. 2004. Available from: http://www.who.int/chp/steps/ syrian_arab_republic/en/index.html. Accessed February 28, 2012.

11. Pitsavos C, Panagiotakos D, Chrysohoou C, Stefanadis C. Epidemiology of cardiovascular risk factors in Greece: aims, design, and baseline characteristics of the ATTICA study. BMC Public Health. 2003;3:32.

12. Erem C, Arslan C, Hacihasanoglu A, et al. Prevalence of obesity and associated risk factors in a Turkish population (Trabzon city, Turkey). Obes Res. 2004;12(7):1117-1127.

13. Aranceta Bartrina J. Prevalence of obesity in developed countries: current status and perspectives. Nutr Hosp. 2002;17 Suppl 1:34-41. Spanish.

14. Streib L. World's fattest countries. In: Forbes.com [website on the Internet]. August 2, 2007. Available from: http://www. forbes.com/2007/02/07/worlds-fattest-countries-forbeslife-cx 1s_0208worldfat_2.html. Accessed February 3, 2012.

15. Al Rashdan I, Al Nesef Y. Prevalence of overweight, obesity, and metabolic syndrome among adult Kuwaitis: results from communitybased national survey. Angiology. 2010;61(1):42-48

16. Ganova-Iolovska M, Kalinov K, Geraedts M. Quality of care of patients with acute myocardial infarction in Bulgaria: a cross-sectional study. BMC Health Serv Res. 2009;9:15.

17. World Health Organization and Ministry of Health Joint Report. Survey of chronic disease prevalence and risk factors. Statistical Survey. Damascus: Ministry of Health, Department of Chronic Diseases; 2002.

18. Skinner AC, Steiner MJ, Henderson FW, Perrin EM. Multiple markers of inflammation and weight status: cross-sectional analyses throughout childhood. Pediatrics. 2010;125(4):e801-e809.
19. Zimmermann E. Lifelong excess mortality in obese young men. Paper presented at: 11th International Congress on Obesity; July 11-15, 2010. Stockholm, Sweden.

20. Topol EJ, editor. Textbook of Cardiovascular Medicine. 3rd ed. Philadelphia, PA: Lippincot Williams and Wilkins; 2007.

21. Tu W, Eckert G, DiMeglio L, et al. Effects of body mass index (BMI) is minimal until extreme values for BMI are reached. Paper presented at: High Blood Pressure Research 2010 Scientific Sessions; October 13-16, 2010; Washington, DC

22. Carson V, Janssen I. Volume, patterns, and types of sedentary behavior and cardio-metabolic health in children and adolescents: a crosssectional study. BMC Public Health. 2011;11:274.

23. Ying AK, Hassanain HH, Roos CM, et al. Methylation of the estrogen receptor-alpha gene promoter is selectively increased in proliferating human aortic smooth muscle cells. Cardiovasc Res. 2000;46(1): 172-179.

24. Bilbo SD, Tsang V. Enduring consequences of maternal obesity for brain inflammation and behavior of offspring. FASEB J. 2010;24(6): 2104-2115.

25. Shankar K, Harrell A, Liu X, Gilchrist JM, Ronis MJ, Badger TM. Maternal obesity at conception programs obesity in the offspring. $\mathrm{Am}$ J Physiol Regul Integr Comp Physiol. 2008;294(2):R528-R538.

26. Ng SF, Lin RC, Laybutt DR, Barres R, Owens JA, Morris MJ. Chronic high-fat diet in fathers programs $\beta$-cell dysfunction in female rat offspring. Nature. 2010;467(7318):963-966.

27. Hu FB, Li TY, Colditz GA, Willett WC, Manson JE. Television watching and other sedentary behaviors in relation to risk of obesity and type 2 diabetes mellitus in women. JAMA. 2003;289(14):1785-1791.

28. Curtis BM, O'Keefe JH Jr. Understanding the Mediterranean diet. Could this be the new "gold standard" for heart disease prevention? Postgrad Med. 2002;112(2):35-38, 41-45.

29. Bashour HN. Survey of dietary habits of in-school adolescents in Damascus, Syrian Arab Republic. East Mediterr Health J. 2004;10(6): 853-862.

30. Sloth B, Krog-Mikkelsen I, Flint A, et al. No difference in body weight decrease between a low-glycemic-index and a high-glycemicindex diet but reduced LDL cholesterol after 10-wk ad libitum intake of the low-glycemic-index diet. Am J Clin Nutr. 2004;80(2): 337-347.

31. Pereira MA, Swain J, Goldfine AB, Rifai N, Ludwig DS. Effects of a low-glycemic load diet on resting energy expenditure and heart disease risk factors during weight loss. JAMA. 2004;292(20):2482-2490.

32. Amir LH, Donath S. A systematic review of maternal obesity and breastfeeding intention, initiation and duration. BMC Pregnancy Childbirth. 2007;7:9.

33. Chouchane L, Mamtani R, Al-Thani MH, Al-Thani AA, Ameduri M, Sheikh JI. Medical education and research environment in Qatar: a new epoch for translational research in the Middle East. $J$ Transl Med. 2011;9:16.
Vascular Health and Risk Management

\section{Publish your work in this journal}

Vascular Health and Risk Management is an international, peerreviewed journal of therapeutics and risk management, focusing on concise rapid reporting of clinical studies on the processes involved in the maintenance of vascular health; the monitoring, prevention and treatment of vascular disease and its sequelae; and the involvement of

\section{Dovepress}

metabolic disorders, particularly diabetes. This journal is indexed on PubMed Central and MedLine. The manuscript management system is completely online and includes a very quick and fair peer-review system, which is all easy to use. Visit http://www.dovepress.com/ testimonials.php to read real quotes from published authors. 